\title{
A SERVICE-ORIENTED MANUFACTURING PARADIGM. A REVIEW PAPER
}

\author{
JULIA SIDERSKA, KHAIR S. JADAAN
}

\begin{abstract}
A B S T R A C T
This paper introduces cloud manufacturing (CMfg) as a new manufacturing paradigm that joins the emerging technologies - such as the Internet of Things, cloud computing, and service-oriented technologies - for solving complex problems in manufacturing applications and performing large-scale collaborative manufacturing. Using scientific publications indexed in Scopus database during the period 2012-2017, the concept and fundamentals of CMfg are presented and discussed given the results of the most recent research. While focusing on the current state of the art, the recent research trends within $\mathrm{CMfg}$ concept were also identified. The review involved the methods of bibliometric analysis and network analysis. A prototype of CMfg and the existing related work conducted by various researchers are presented, and the map of co-occurrence is introduced to indicate the most commonly occurring issues related to the "cloud manufacturing" term. The VOSviewer software was used for this purpose. Finally, cloud-based manufacturing areas for further research are identified.
\end{abstract}

KEY WORDS

cloud manufacturing, concept, co-occurrence, service-oriented, manufacturing resources, paradigm

DOI: 10.1515/emj-2018-0002
Corresponding author:

Julia Siderska

Bialystok University of Technology, Faculty of Engineering Management, Poland e-mail: j.siderska@pb.edu.pl

Khair S. Jadaan

University of Jordan, Department of Civil Engineering, Jordan e-mail: kjadaan@gmail.com

\section{INTRODUCTION}

As the global competition in the manufacturing sector is constantly rising and at the same time the exploitation of Big Data can dramatically increase the manufacturing efficiency, a completely new manufacturing paradigm, namely, cloud manufacturing, which received much interest from researchers, is gaining a growing attention in the industry sector
(Mourtzis \& Vlachou, 2016). The present paradigm assumes that the modern manufacturing industry is currently being transformed into global manufacturing networks and supply chains allowing the common used of globally distributed manufacturing systems and resources. The cloud manufacturing concept is considered as one of the main directions in the development of the manufacturing industry (Yuan et al., 
2017). Among other researchers, Zhang studied three core components for constructing a CMfg system, namely, CMfg resources, the manufacturing cloud service, and the manufacturing cloud. They also investigated the constructing method for the manufacturing cloud (Zhang et al., 2014).

Cloud manufacturing is an emerging paradigm in which dynamically scalable and virtualised manufacturing resources, abilities and capabilities involved in the whole lifecycle are provided to the users in the form of services over the Internet in a pay-as-yougo manner. Based on novel technologies like SOA (service-oriented architecture) and cloud computing, cloud manufacturing is a solution where users can request services ranging from product design, manufacturing, testing, management and all other stages of a product lifecycle (Talhi, 2015). The emergence of cloud computing initiated a new paradigm of servitisation, assuming the change of a physical product (software or hardware) into a service. Cloud manufacturing, as a model integrating innovative technologies (the Internet of Things, cloud computing, service-oriented technologies, virtualisation, semantic web, advanced high-performance computing technologies) with advanced manufacturing, enables and supports cooperation, sharing and management of manufacturing resources. These resources and know-hows - e.g. software tools, knowledge, applications, equipment, fabrication - capabilities, etc. - of manufacturing companies can be inserted into the cloud and thereby become accessible to presumptive consumers (Adamson et al., 2017).

This paper is organised as follows: Section 1 determines the methodology involved in the research process, including bibliometric analysis and the use of the VOSviewer software. It also proves that the cloud manufacturing concept has been gaining growing attention among the academia and the industry. Section 2 provides a brief discussion of cloud manufacturing paradigm and presents definitions of this concept selected from the literature. Sections 3 and 4 pose the analytical part of the paper. Section 3 presents the results of the conducted review, mainly including the identification of the top authors researching the cloud manufacturing concept as well as their affiliated universities or research centres. This part of paper also indicates the most popular journals chosen by the authors. All those results reflect increasing attention among researchers in Europe and all over the world. Section 4 introduces the network of co-occurrence with research areas related to the scope of cloud manufacturing. On this basis, it was possible to identify the sub-areas of research in the field of cloud manufacturing as well as the strength of connections, relations and the cooccurrence between them. Section 5 introduces service-oriented future directions of research, related to cloud manufacturing concept. Conclusions are given in Section 6.

\section{Methodology}

To analyse the current interest of researchers in the field of cloud manufacturing, the authors explored publications collected in three leading scientific databases: Web of Science (WoS Core collection), IEEE Xplore Digital Library, and Scopus. As the term "cloud manufacturing" appeared for the first time in the scientific literature in 2010, the bibliometric analysis was conducted based on data accordingly from 2010 to 2017. Fig. 1 presents the number of publications indexed in the databases in the specified period. The figure indicates the growing popularity of cloud manufacturing research.

In the analysed period, the number of publications indexed in the IEEE database was 110, whereas Web of Science had 458 and Scopus - 811. It can be observed that the interest of scientists in this research area increased rapidly in 2012 and augmented considerably in the past few years. It is worth indicating that the number of papers referring to the cloud manufacturing concept, found in Scopus, was much higher than in WoS and IEEE databases. This identified the trend of the researcher interest and was the premise for the authors to analyse further the publications indexed in the Scopus database released in 2012-2017. 766 matches have been found as the result of exploring the Scopus database, using "cloud manufacturing" as a search phrase in titles, abstracts and keywords, and limiting the publishing period to 2012-2017. In the opinion of the authors, the total number of publications in this field indexed in all explored databases is still low, despite the evergrowing importance of key and innovative technologies within the Industry 4.0. The academia and the industrial sector all over the world consider cloud manufacturing as an emerging and promising paradigm as well as a business model, enabling the transformation of the manufacturing industry towards the digital and smart industrial revolution. This means there should be more scientific considerations on cloud manufacturing concepts. 


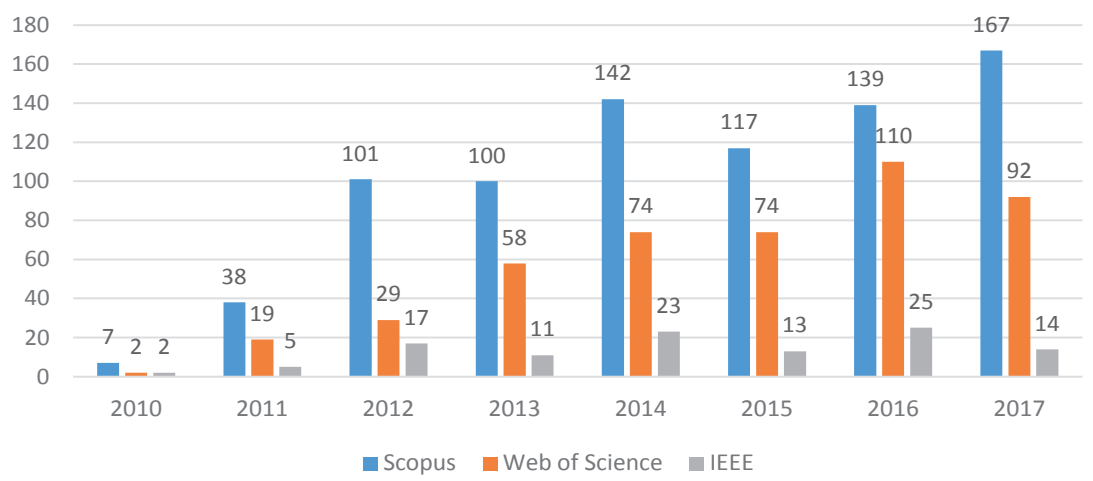

Fig. 1. Number of publications indexed in 2010-2017 in WoS, Scopus and IEEE databases referring to the cloud manufacturing concept

Source: elaborated by the authors based on (http://bazy.pb.edu.pl).

The next step of the research process was to export the received set of selected publications to *. csv file and implement those data in the VOSviewer environment. VOSviewer is a software tool for map creation based on network data helping to visualise and explore these networks. Constructed maps may include networks of scientific publications, journals, researchers and affiliations, countries, keywords or terms. Items can be related by co-authorship, cooccurrence, citations (as well as co-citations) and bibliographic links. The VOSviewer software helps to construct and visualise a map of important terms as well as the connections between the elements extracted from the body of scientific publications indexed in Web of Science and Scopus database. The authors examined Scopus database as the most substantial resource to prepare a bibliometric map and visualise the co-occurrence of areas connected with cloud manufacturing. This issue is scrutinised and discussed in detail in Section 4.

\section{CLOUD MANUFACTURING: THE CONCEPT SYSTEM AND ASSUMPTIONS}

Research on cloud manufacturing mainly revolves around the CMfg concept itself and the architecture and function implementations of cloud manufacturing platforms (Liu et al., 2016). No single commonly accepted and cited definition of cloud manufacturing has been proposed so far in the scientific discourse; however, the researchers elaborated on a comprehensive prospect of what cloud manufac- turing would comprehend and facilitate (Adamson et al., 2017). The literature review allowed to identify several, frequently cited definitions. The first pioneering attempt to explain and characterise this concept was made by $\mathrm{Li}(\mathrm{Li}, 2010)$, and since then, this concept attracted much attention. Tab. 1 contains few cloud manufacturing definitions chosen by the authors subjectively as a result of a comprehensive scientific literature overview.

It is worth emphasising that most of the researchers determine cloud manufacturing as an emerging, and thereby up-to-date and open concept of virtualising the distributed manufacturing and assembling resources to provide a coherent, uninterrupted and high-quality transaction of the manufacturing process. Cloud computing emerges as one of the major enablers for the manufacturing industry as it can transform the business model and create intelligent networks that encourage effective collaboration within factors $(\mathrm{Xu}, 2011)$. The concept of cloud manufacturing is built on cloud computing, the Internet of Things, cyber-physical systems, the networked manufacturing, service-oriented manufacturing, virtual manufacturing and the virtual enterprise (Ren et al., 2015).

Three categories of key stakeholders were identified: providers, operators, and consumers. Providers publish their resources to the cloud manufacturing platform (the published resources are then encapsulated into the service platform), operators manage all aspects of the platform that are relevant to the platform running and operation, and consumers request services from the cloud platform. Typically, a cloud manufacturing platform consists of five layers, namely, resource layer, virtual resource layer, global 
Tab. 1. Selected definitions of the cloud manufacturing concept

\begin{tabular}{|c|c|}
\hline AUTHOR(s) & DEFINITION \\
\hline Li et al., 2010 & $\begin{array}{l}\text { New networked manufacturing paradigm that organizes manufacturing resources over networks } \\
\text { (manufacturing clouds) according to consumers' needs and requirements to provide a variety of } \\
\text { on-demand manufacturing services via networks (e.g., Internet) and cloud manufacturing service } \\
\text { platforms }\end{array}$ \\
\hline Wu \& Yang, 2010 & $\begin{array}{l}\text { An integrated supporting environment both for the share and integration of resources in enterprise. } \\
\text { It provides virtual manufacturing resources pools, which shields the heterogeneousness and } \\
\text { the regional distribution of resources by the way of virtualization. Cloud manufacturing provides } \\
\text { a cooperative work environment for manufacturing enterprises and individuals and enables } \\
\text { the cooperation of enterprise }\end{array}$ \\
\hline Tao et al., 2011 & $\begin{array}{l}\text { A new service-oriented manufacturing model, which integrates different technologies, such as } \\
\text { networked manufacturing, cloud computing, Internet of Things (IoT), virtualisation and service- } \\
\text { oriented technologies to support collaboration, sharing and management of manufacturing resources }\end{array}$ \\
\hline Xu, 2012 & $\begin{array}{l}\text { A model for enabling ubiquitous, convenient, on-demand network access to a shared pool of } \\
\text { configurable manufacturing resources (e.g. manufacturing equipment, manufacturing capabilities and } \\
\text { manufacturing software tools) that can be rapidly provided and released with minimal management } \\
\text { effort or service provider interaction }\end{array}$ \\
\hline Macia-Perez et al., 2012 & $\begin{array}{l}\text { A new model of manufacturing services, infrastructure and technology that allows users access to } \\
\text { a catalogue of standardized services and meet the needs of your business, in a flexible and adaptive } \\
\text { form, in case of unforeseen demand or peak workloads, paying only for consumption made }\end{array}$ \\
\hline Wang et al., 2014 & $\begin{array}{l}\text { An integrated cyber-physical system that can provide on-demand manufacturing services, digitally and } \\
\text { physically, at the best utilisation of manufacturing resources }\end{array}$ \\
\hline Adamson et al., 2017 & $\begin{array}{l}\text { A network manufacturing model in which locally and globally distributed manufacturing resources for } \\
\text { the complete product life-cycle are made available by providers for satisfying consumer demands, and } \\
\text { re centrally organised and controlled as manufacturing Cloud services. The model supports unified } \\
\text { interaction between service providers and consumers, for trading and usage of configurable } \\
\text { resources/services, as well as dynamic and flexible cooperation and collaboration in multi-partner } \\
\text { manufacturing missions. Distinct characteristics for the use are that they are scalable, sold on } \\
\text { demand, and fully managed by the provider }\end{array}$ \\
\hline
\end{tabular}

Source: elaborated by the authors based on the conducted literature review.

service layer, application layer and user interface layer (Xu, 2012).

Most researchers consider the cloud manufacturing concept as an extension of the cloud computing idea to manufacturing, wherein capabilities and resources are componentised, integrated, optimised and provisioned globally. All of them stress the significant role of innovative technologies, such as the Internet of Things, cloud computing, service-oriented technologies, virtualisation, the semantic web, and the need of integrating them with the advanced manufacturing. In this context, cloud manufacturing should be considered as a modern business model enabling the virtualisation of manufacturing resources, sharing and offering them as cloud-based services over the Internet. Consequently, the industry sector is dealing with the transformation from traditional, production-oriented towards integrated and service-oriented manufacturing.
Although the literature suggests different cloud manufacturing definitions and focuses on unique aspects of this concept, it considers similar components, such as the networked manufacturing, resource sharing, service-oriented technologies, virtualisation, collaboration, cloud computing, and everything-asa-service (IaaS, Paas, Saas, Haas).

Liu et al. (2016) discussed and compared the concepts of the Industry 4.0 and cloud manufacturing based on their basic ideas and research statuses. They concluded that from the perspective of the concept system, the Industry 4.0 is a broader concept than cloud manufacturing because it encompasses both intra-factory and inter-factory integration, whereas cloud manufacturing concentrates on the latter. 


\section{CURRENT RESEARCH WITHIN CLOUD MANUFACTURING}

As shown in Fig. 1, cloud manufacturing paradigm has been growing in popularity among researchers over the past few years. It is significant that the researchers dealing with the issue of cloud manufacturing affiliate mainly with Chinese universities and units. Tab. 2 presents the top 14 global scientists in the field of cloud manufacturing as well as the number of their publications indexed in the Scopus database in 2012-2017. Among all the authors, the following should be undoubtedly distinguished: Zhang, Tao and Ren from Beihang University in China, Wang from the Royal Institute of Technology (Sweden) and $\mathrm{Xu}$ from the University of Auckland (New Zealand). It should be emphasised that the majority of all 766 examined publications were affiliated with Chinese universities and units (510), whereas 60 papers were written by authors from the United States, 47 from Sweden, 46 from the United Kingdom, and 43 from New Zealand. A much smaller number of the publication was published by researchers from Germany (19), Taiwan (18), Canada (15),

Tab. 2. Top authors of scientific publications on the topic of cloud manufacturing in 2012-2017

\begin{tabular}{|c|c|c|}
\hline AUTHOR & AfFiLiation & $\begin{array}{l}\text { NUMBER OF } \\
\text { PUBLICATIONS }\end{array}$ \\
\hline Zhang L. & Beihang University (China) & 61 \\
\hline Tao F. & Beihang University (China) & 44 \\
\hline Wang L. & $\begin{array}{l}\text { The Royal Institute of } \\
\text { Technology (Sweden) }\end{array}$ & 35 \\
\hline XuX. & $\begin{array}{l}\text { University of Auckland } \\
\text { (New Zealand) }\end{array}$ & 30 \\
\hline Ren L. & Beihang University (China) & 26 \\
\hline Xu W. & Ministry of Education (China) & 19 \\
\hline Wang X. V. & $\begin{array}{l}\text { The Royal Institute of } \\
\text { Technology (Sweden) }\end{array}$ & 18 \\
\hline Liu Y. & Beihang University (China) & 17 \\
\hline Liu Q. & $\begin{array}{l}\text { Wuhan University of Technology } \\
\text { (China) }\end{array}$ & 16 \\
\hline Yin C. & Chongqing University (China) & 16 \\
\hline Zhou Z. & $\begin{array}{l}\text { Wuhan University of Technology } \\
\text { (China) }\end{array}$ & 16 \\
\hline Kang L. & Chongqing University (China) & 14 \\
\hline Yao X. & $\begin{array}{l}\text { South China University of } \\
\text { Technology (China) }\end{array}$ & 14 \\
\hline Yang $\mathrm{C}$. & Western University (Canada) & 13 \\
\hline
\end{tabular}

Source: elaborated by the authors based on the Scopus database.
Finland (11), Greece (11), Iran (10), and Hong Kong (8).

Tab. 3 presents selected authors representing European universities and research centres. Most of them affiliate with Swedish units (the Royal Institute of Technology and University of Skövde) as well as the University of Vaasa in Finland, and the University of Bath and the University of Birmingham in the United Kingdom. The Scopus database has only five papers authored by Polish researchers and one paper by a Jordanian author with "cloud manufacturing" phrase indicated in titles, abstracts and keywords and published in the years 2012-2017.

Tab. 3. Selected European researchers publishing on the topic of cloud manufacturing

\begin{tabular}{|l|l|r|}
\hline \multicolumn{1}{|c|}{ AUtror } & \multicolumn{1}{|c|}{ AfFiliation } & \multicolumn{1}{|c|}{$\begin{array}{c}\text { NUMBER OF } \\
\text { PUBLICATIONS }\end{array}$} \\
\hline Wang L. & $\begin{array}{l}\text { The Royal Institute of } \\
\text { Technology (Sweden) }\end{array}$ \\
\hline Wang X. V. & $\begin{array}{l}\text { The Royal Institute of } \\
\text { Technology (Sweden) }\end{array}$ \\
\hline Schaefer D. & $\begin{array}{l}\text { University of Bath (United } \\
\text { Kingdom) }\end{array}$ \\
\hline Pham D. T. & $\begin{array}{l}\text { University of Birmingham } \\
\text { (United Kingdom) }\end{array}$ \\
\hline Adamson G. & University of Skövde (Sweden) & 9 \\
\hline Mourtzis D. & University of Patras (Greece) & 7 \\
\hline Hao Y. & University of Vaasa (Finland) & 5 \\
\hline Helo P. & University of Vaasa (Finland) & 5 \\
\hline
\end{tabular}

Source: elaborated by the authors based on the Scopus database.

The paper "From cloud computing to cloud manufacturing" published in 2012 by Xu in the journal titled "Robotics and Computer-Integrated Manufacturing" was the most frequently cited article in the area of cloud manufacturing of all times (Xu, 2012). It was cited by 940 researchers accordingly to Google Scholar database and almost 600 times as per Scopus. Professor Xu from the University of Auckland in New Zealand is globally considered to be one of the pioneers in cloud manufacturing research. The index of citation of this paper, considered as a fundamental one in this field, proves the global trend within this concept. However, most academics and industries focus on implementing the Industry 4.0 technologies, mainly IoT, CPS, and Big Data, rather than cloud manufacturing. In the opinion of the authors, the investigations within this concept emerge as an interesting research gap. 
Scientific papers related to the field of cloud manufacturing were published in the analysed period 2012-2017 in various journals indexed in the Scopus database. Tab. 4 presents the most popular journals to which considered papers were submitted. Among all studied publications, the largest number was published in the following journals: Computer Integrated Manufacturing Systems (103), International Manufacturing Science and Engineering (58) and International Journal of Advanced Manufacturing Technology (45). The following journals also attracted great interest among researchers: Applied Mechanics and Materials, Procedia CIRP and Advanced Materials Research.

Among all 766 investigated publications referring to the cloud manufacturing concept, two main research areas of publication qualification were easy to identify, namely, engineering (581 papers) and computer science (451).

The publications were also assigned to the areas of mathematics (107), decision science (69) as well as business, management and accounting (50). Only a few of them were ranked among material science, energy and physics and astronomy.

In their papers, a vast majority of authors mentioned above introduce the platform technologies, ontologies, multi-task scheduling (Liu et al., 2017), programming models, file systems as well as system architectures (layers) for the development of cloud manufacturing platforms ( $\mathrm{He} \& \mathrm{Xu}, 2015)$. They also often investigate information and communication models and new business models referring to this concept (Wu et al., 2014). Several examined publications mentioned the issues of manufacturing resources and capabilities. All manufacturing capabilities require support from the related manufacturing resources, including soft resources (software, engineering knowledge, skills, experience, business networks, etc.) and hard resources, for instance, manufacturing equipment, computational resources, monitoring resources, storage, etc. (Wang \& Xu, 2013).

\section{CO-OCCURRENCE OF RELATED AREAS}

The crowning step within the conducted bibliometric analysis was to identify the relations among cloud manufacturing research areas as well as the cooccurrence links between this phrase and other connected items as well as to determine co-authorship links between researchers. Fig. 2 presents the map of research sub-areas, and their contents, related to cloud manufacturing, prepared with the use of the VOSviewer software. The network was developed based on keywords indicated by authors of examined publications. Individual items (areas) are represented by their labels and circles. The size of the item is determined by its weight. The higher the weight of each considered item (the higher the frequency of occurrence of the term), the larger the circle of it. Moreover, the most frequently occurring keywords are situated in the central part of the map (Gudanowska, 2017b).

The distance between those areas approximately indicates their relatedness in terms of co-occurrence links. In general, the closer two terms are located to each other, the stronger is their relatedness, measured by co-occurrences. Moreover, the strongest co- 


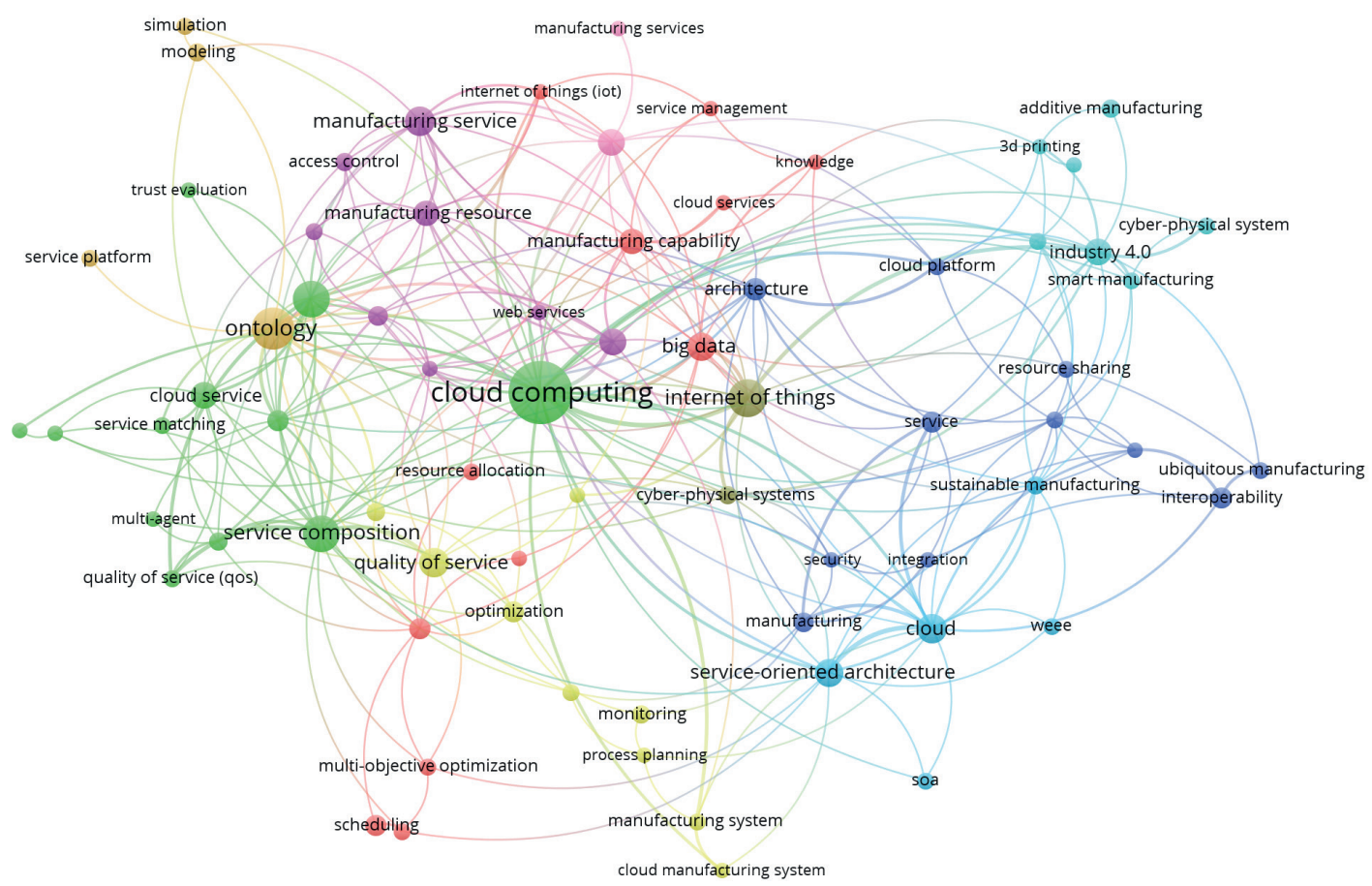

Fig. 2. Map of co-occurrence with research areas related to the scope of cloud manufacturing from the Scopus database in 2012-2017 Source: elaborated by the authors based on (http://bazy.pb.edu.pl) with the use of the VOSviewer software.

occurrence links between terms are also represented by lines. Each link has a strength, represented by a positive numerical value. The higher this value, the stronger the link. For the purpose of this paper, the strength of the link indicates the number of publications, in which terms occur together. The horizontal and vertical axes have no special meaning, and the maps can be freely rotated and flipped. Colours indicate clusters of closely related terms (van Eck \& Waltman, 2017).

To ensure the map's transparency, the authors have chosen five as the minimum number of keywords considered for the purpose of this analysis (Gudanowska, 2017a). Among all of 1676 keywords indicated by authors of analysed publications, 73 met this threshold. For each of these 73 keywords, the total strength of the co-occurrence links with other keywords was calculated.

Fig. 2 presents the map of co-occurrence representing the items referring to terms found more than five times in all analysed publications. The results should be analysed considering the size of the circles as well as the distance between them. In general, the bigger the circle, the higher is the occurrence of a term (Olszewska, 2016). Analysing Fig. 2, it is noticeable that in the considered papers the most frequently occurring terms are as follow (the largest circles): cloud computing (84), ontology (38), cloud manufacturing-cmfg (28), Internet of Things (30), service composition (27) and cloud (19). Worth specifying are also other frequently occurring items: manufacturing service (18), quality service (18), big data (16), service-oriented architecture (16), Industry 4.0 (15), cloud service (15), manufacturing resource (14) and manufacturing capability (13). The number of occurrences of each phrase is given above in brackets. Moreover, the thickness of the line connecting the items should also be considered. The more significant is the weight of a co-occurrence, the thicker is the line. The total link strength includes the items as follow: cloud, cloud computing, service-oriented manufacturing, ontology, service composition, resource sharing, service-oriented architecture and the Industry 4.0. It should also be emphasised that the network of co-occurrences consists of many connections, reflecting and confirming numerous coexistences between those keywords.

The construction of the co-occurrence network presented in Fig. 2 allowed concurrently to point out 10 areas (clusters) gathering the terms most frequently appearing together in publications related to the cloud manufacturing concept. Considering scientific interests of the authors and further research areas the selected and most important of them included 
the following items: cluster 1 (red): big data, cloud service, genetic algorithm, Internet of Things, knowledge, manufacturing capabilities, multi-objective optimization, particle swarm optimization, product design, resource allocation, scheduling, service management; cluster 2 (green): cloud computing, cloud manufacturing $(\mathrm{cmfg})$, cloud manufacturing platform, cloud manufacturing service, cloud service, optimal selection, multi-agent, quality of service (qos), semantic web, service composition, service matching, trust evaluation; cluster 3 (dark blue): architecture, cloud platform, integration, interoperability, interoperable manufacturing, resource sharing, ubiquitous manufacturing; manufacturing system, manufacturing resource, manufacturing, security, service; cluster 4 (yellow): cloud manufacturing system, knowledge management, manufacturing resource, manufacturing system, monitoring, optimization, process planning, quality of service, service selection; cluster 5 (pink): access control, cloud manufacturing service, manufacturing cloud, manufacturing cloud service, manufacturing resource, manufacturing service, virtualisation, web services; cluster 6 (cyan): 3D printing, additive manufacturing, collaborative manufacturing, distributed manufacturing, smart manufacturing, cyber-physical system, industry 4.0, cluster 7: cloud, SOA, service-oriented architecture, sustainable manufacturing, weee; cluster 8: modelling, ontology, service platform, simulation.

\section{FUTURE RESEARCH TRENDS}

The cloud manufacturing concept focuses on the configuration and modelling of manufacturing services. The authors identified key service-oriented technologies, enabling cloud manufacturing: serviceoriented architecture (SOA), web service, enterprise service bus, semantic web, ontology (He \& Xu, 2015). Considering and acknowledging the service-oriented character of CMfg, the authors also explored the current and topical literature to identify up-to-date and promising research areas within cluster $\# 5$ mentioned above, referring to services, gathering following items: cloud manufacturing service, manufacturing cloud service, manufacturing service, virtualisation and web services. Among the essential directions of the future research, related to services, the following should be mentioned:

- efficiently and cost-effectively converting manufacturing resources and capabilities into services and placing them in cloud-based platforms (Zhong et al., 2017);

- the development of effective algorithms of managing resource service transactions (Tao et al., 2012);

- the development of optimisation algorithms and strategies to support comprehensive QoS management to achieve high quality and efficiency (He \& Wu, 2015);

- QoS-based service composition selection in a cloud manufacturing system (Zhong et al., 2017);

- the introduction of semantic models for manufacturing resources and capability servitisation and data sharing (Xie et al., 2017);

- the development of the algorithms for data quality management (Song et al., 2017);

- the elaboration of optimisation algorithms for optimal service composition in the cloud environment with the consideration of service correlations (Zhou \& Yao, 2017);

- manufacturing services configuration (Zhong et al., 2017);

- robust service compositions that are autonomously reconfigured with minimal human intervention (Wu et al., 2013);

- service encapsulation and virtualisation access models for manufacturing machines, combining the Internet of Things techniques and cloud computing (Zhang et al., 2017);

- protocol, safety and security, reliability, and management techniques of application in CMfg systems (Yuan et al., 2017);

- the development of the trust evaluation models increases the credibility of service transaction trust evaluation in CMfg systems (Yan et al., 2015).

Beside cloud-based manufacturing, the authors also identified the most recent manufacturing concepts that appeared in literature: smart manufacturing, sustainable manufacturing, green manufacturing, social manufacturing, nanomanufacturing, additive $+3 \mathrm{~d}$ printing manufacturing, advanced manufacturing, remanufacturing and cyber-physical systems. These paradigms rely on new technologies that enable flexibility, agility, and reconfigure-ability (Esmaeilian \& Behdad, 2016).

The future development of the cloud manufacturing concept will face many challenges in key enabling technologies mentioned above. Besides the integration technologies of cloud computing, IoT, semantic web, high-performance computing and 
embedded systems, several important technical issues must also be solved, such as knowledge-based resource clouding, cloud management engines, collaboration between CMfg applications, and visualisation and user interface in cloud environments (Adamson, 2017).

\section{CONCLUSIONS}

Major of researchers treat cloud manufacturing as an intelligent and collaborative manufacturing service model. Distributed manufacturing resources (e.g. machine tools, 3D printers, computer-aided design, computer-aided manufacturing, mass storages, software, model repository, databases, etc.) and manufacturing capabilities (e.g. design capability, fabrication capability, assembling capability, simulation capability, testing capability, etc.) are interconnected and constitute a shared pool in cloud manufacturing platform. Through cloud manufacturing, customers have on-demand access to services, such as design as a service (Wu et al., 2012), social networking as a service (Wu et al., 2013), simulation as a service (Ren et al., 2011), production as a service, assembling as a service, test as a service, logistics as a service (Ren et al., 2015).

Based on examined publications indexed in the Scopus database during the period 2012-2017, the authors recognised the current global interest of researchers in cloud manufacturing area. Moreover, the conducted literature review enabled the identification of the top authors, journals as well as universities and research centres in Europe and all over the world leading in disseminating the knowledge and latest achievements in the area of cloud manufacturing. The conducted literature overview also allowed to identify current areas of research in the field of issues referring to the cloud manufacturing concept, including and emphasizing mainly the service-oriented features of the CMfg paradigm. This identification of trends was possible based on the created network of co-occurrence between this term and other related phrases.

The conducted comprehensive literature review allowed to recognise the current state of the art within cloud manufacturing. Cloud manufacturing concept is still a poorly defined field of study and would benefit from detailed research in many areas. The authors of publications referring to the cloud manufacturing concept introduced mainly the platform technologies (Ren et al., 2015; Zhang et al., 2014), ontology (Talhi et al., 2015), hard and soft manufacturing resources (Yuan et al., 2017), system architectures (layers) for the development of cloud manufacturing platforms. Some of them proposed several new techniques and approaches to encapsulate virtualised manufacturing resources and capabilities as cloud-based services (Ren et al., 2015). They also provide some research trends within cloud manufacturing concept, discuss potential opportunities, barriers and challenges within the discussed paradigm ( $\mathrm{Wu}$ et al., 2013; Adamson et al., 2017).

Although the cloud manufacturing concept emerges as the consequence and evolution of existing technologies, it is also widely accepted to be the future-oriented, innovative paradigm, which will reform the manufacturing industry. However, the application of cloud manufacturing is still in the initial experimental and testing stage. Many proposed models and algorithms in this area have not been strictly tested in a large-scale cloud manufacturing environment to evaluate their effectiveness, efficiency and feasibility (He \& Xu, 2015). The authors of examined publications focus primarily on theory and framework. Thus, it is necessary to provide the characteristics of actual implementations in practice and introduce some successful approaches and implementations in this area.

\section{ACKNOWLEDGEMENTS}

The research was conducted within S/WZ/1/2014 project and was financed from funds of the Ministry of Science and Higher Education.

\section{LITERATURE}

Adamson, G., Lihui, W., Holm, M., \& Moore, P. (2017). Cloud manufacturing - a critical review of recent development and future trends. International Journal of Computer Integrated Manufacturing, 30(4-5), 347380. doi: 10.1080/0951192X.2015.1031704

van Eck, N. J., \& Waltman, L. (2017). VOSviewer manual. Retrieved from vosviewer.com/download/f-y2z2.pdf

Esmaeilian, B., Behdad, S., \& Wang, B. (2016). The evolution and future of manufacturing: A review. Journal of Manufacturing Systems, 39, 79-100.

Gudanowska, A. E. (2017a). Transformation towards industry 4.0 - identification of research trends and aspect of necessary competences in the light of selected publications. Research in Logistics and Production, 7(5), 431-441. doi: 10.21008/j.2083-4950. 2017.7.5.4 
Gudanowska, A. E. (2017b). A map of current research trends within technology management in the light of selected literature. Management and Production Engineering Review, 8(1), 78-88. doi: 10.1515/mper2017-0009

He, W., \& Xu, L. (2015). A state-of-the-art survey of cloud manufacturing. International Journal of Computer Integrated Manufacturing, 28(3), 239-250. doi: 10.1080/0951192X.2013.874595

Li, B. H., Zhang, L., Wang, S., Tao, F., Cao, J., Jiang, X., \& Song, X. (2010). Cloud manufacturing: a new service-oriented networked manufacturing model. Computer-Integrated Manufacturing Systems, 16(1), $1-8$.

Liu, Y., \& Xu, X. (2016). Industry 4.0 and cloud manufacturing: a comparative analysis. Journal of Manufacturing Science and Engineering, 139(3), 1-8. doi: $10.1115 / 1.4034667$

Liu, Y., Xu, X., Zhang, L., Wang, L., \& Zhong, R. Y. (2017). Workload-based multi-task scheduling in cloud manufacturing. Robotics and Computer-Integrated Manufacturing, 45, 3-20.

Macia-Perez, F., Berna-Martinez, J. V., Marcos-Jorquera, D., Lorenzo-Fonseca, I., \& Ferrandiz-Colmeiro, A. (2012). A new paradigm: cloud agile manufacturing. International Journal of Advanced Science and Technology, 45, 47-54.

Mourtzis, D., \& Vlachou, E. (2016). Cloud-based cyberphysical systems and quality of services. The TQM Journal, 28(50), 704-733. doi.org/10.1108/TQM-102015-0133

Olszewska, A. M. (2017). Research issues undertaken within quality management - the overview of selected literature. Engineering Management in Production and Services, 9(1), 74-83. doi: 10.1515/emj2017-0008

Ren, L., Zhang, L., Tao, F., Zhao, Ch., Chai, X., \& Zhao, X. (2015). Cloud manufacturing: from concept to practice. Enterprise Information Systems, 9(2), 186-209. doi: 10.1080/17517575.2013.839055

Ren, L., Zhang, L., Zhang, Y., Tao, F., \& Luo, Y. (2011). Resource virtualization in cloud manufacturing. Computer-Integrated Manufacturing Systems, 17(3), 511-518.

Song, Z. T., Sun, Y. M., Wan, J. F., \& Liang, P. P. (2017). Data quality management for service-oriented manufacturing cyber-physical systems. Computers and Electrical Engineering, 64, 34-44. doi: 10.1016/j. compeleceng.2016.08.010

Talhi, A., Huet, J. C., Fortineau, V., \& Lamouri, S. (2015). Towards a cloud manufacturing systems modeling methodology. IFAC-PaperOnLine, 48(3), 288-293. doi.org/10.1016/j.ifacol.2015.06.096

Tao, F., Cheng, Y., Zhang, L., \& Zhao, D. (2012). Utility modeling, equilibrium and collaboration of resource service transaction in service-oriented manufacturing. Proceedings of the Institution of Mechanical Engineers Part B: Journal of Engineering Manufacture, 226(6), 1099-1117.
Wang, X. V., \& Xu, X. (2013). An interoperable solution for cloud manufacturing. Robotics and Computer-Integrated Manufacturing, 29(4), 232-247. doi. org/10.1016/j.rcim.2013.01.005

Wu, D., Greer, M. J., Rosen, D. W., \& Schaefer, D. (2013). Cloud manufacturing: strategic vision and state-ofthe-art. Journal of Manufacturing Systems, 32(4), 564-579.

Wu, D., Rosen, D. W., Wang, L., Schaefer, D. (2014). Cloudbased manufacturing: old wine in new bottles? Variety Management in Manufacturing. Proceedings of the 47th CIRP Conference on Manufacturing Systems. Procedia CIRP, 17, 94-99. doi.org/10.1016/j.procir.2014.01.035

Wu, D., Thames, J. L., Rosen, D. W., \& Schaefer, D. (2012). Towards a cloud-based design and manufacturing paradigm: looking backward, looking forward. Proceedings of the ASME 2012 International Design Engineering Technical Conference \& Computers and Information in Engineering Conference, 2, 315-328. doi 10.1115/DETC2012-70780

Xie, Ch., Cai, H., Xu, L., Jiang, L., \& Bu, F. (2017). Linked semantic model for information resource service toward cloud manufacturing. IEEE Transactions on Industrial Informatics, 13(6), 3338-3350.

Xu, X., (2012). From cloud computing to cloud manufacturing. Robotics and Computer-Integrated Manufacturing, 28, 75-86. doi.org/10.1016/j.rcim.2011.07.002

Yan, K., Cheng, Y., \& Tao, F. (2016). A trust evaluation model towards cloud manufacturing. International Journal of Advanced Manufacturing Technologies, 84(1-4), 133-146. doi: 10.1007/s00170-015-8002-5

Yuan, M., Deng, K., \& Chaovalitwongse, W. A. (2017). Manufacturing Resource Modeling for Cloud Manufacturing. International Journal of Intelligent Systems, 32(4), 414-436. doi: 10.1002/int.21867

Zhang, L., Luo Y., Tao, F., Li, B., Ren, L., Zhang, X., Guo, H., Cheng, Y., Hu, A., \& Liu, Y. (2014). Cloud manufacturing: a new manufacturing paradigm. Enterprise Information System, 8(2), 167-187.

Zhang, Y. F., Zhang, G., Liu, Y., \& Hu, D. (2017). Research on services encapsulation and virtualization access model of machine for cloud manufacturing. Journal of Intelligent Manufacturing, 28(5), 1109-1123. doi: 10.1007/s10845-015-1064-2

Zhong, R. Y., Xu, X., Klotz, E., \& Newman, S. T. (2017). Intelligent manufacturing in the context of industry 4.0: a review. Engineering, 3(5), 616-630.

Zhou, J. J., \& Yao, X. F. (2017). Hybrid teaching-learningbased optimization of correlation-aware service composition in cloud manufacturing. International Journal of Advanced Manufacturing Technology, 91(9-12), 3515-3533. doi: 10.1007/s00170-0170008-8 